EDI TORI AL

\title{
La publicidad comercial de medicamentos también es corrupción
}

La corrupción es hoy un rasgo presente a escala mundial. Siempre hay excepciones, pero están resultando muy escasas. En Cuba se lucha contra este flagelo, se ha sancionado ejemplarmente al más alto nivel, pero reaparece, aunque no con la frecuencia y magnitud que en los centros del capitalismo neoliberal, donde es práctica común en las altas esferas (gobierno) y en las más visibles empresas privadas.

En el sistema de salud cotidianamente hablamos de "pequeñas corrupciones", que nunca serán pequeñas, pues tienen el mismo significado moral, político o social que los grandes fraudes. También deben ser denunciadas, combatidas.

Entre las consideradas "pequeñas" se cuentan la receta de complacencia, la violación en una lista de espera, el obsequio injustificado, la venta de un servicio y otras.

Trascendente es el fraude científico o académico, donde se adulteran datos en investigaciones y publicaciones científicas, el plagio, la atribución de autoría falsa o presentar como un ensayo clínico válido aquello que no lo es por no cumplir con las normas exigidas.

Estas formas de corrupción en los servicios, en la investigación y en la publicación científica eran prácticamente desconocidas en las tres primeras décadas de la Salud Pública Revolucionaria cubana.

Los avatares en la lucha contra las agresiones del imperio, la influencia del auge de la corrupción a escala mundial, los problemas del "período especial" padecido por el país en los últimos años, el incremento de las investigaciones en todo el país, la tolerancia -recurrente ausencia de sanciones-, provocan la peligrosa situación actual que propicia un aumento de las formas de corrupción mencionadas.

También es corrupción la falta de ética, tal como la reaparición en la prensa no especializada de publicidad que anuncia un producto con propiedades terapéuticas, muy notables y específicas: analgésico, antiinflamatorio y antitumoral.

El anuncio afirma que estos son valores "probados". Pero esos efectos solo se prueban mediante ensayos clínicos controlados, que no aparecen a pesar de intensa búsqueda en las revistas científicas cubanas o extranjeras y que en una sesión de trabajo sostenida con la participación de los productores, investigadores de otros centros y periodistas, su inexistencia fue reconocida.

El anuncio se refiere al vidatox, elaborado por el Grupo Empresarial Labiofam. En el texto se dice que se trata de un "producto homeopático", en la etiqueta de los frascos - aparecen en el anuncio- dice que es un "medicamento homeopático". Este último es el que se promociona.

El anuncio consigna que el producto está inscrito en el Centro de Control Estatal de la Calidad de los Medicamentos (CECMED), y esto lo dice en el párrafo que presenta el 
producto homeopático, al que no se le exige tener ensayos clínicos controlados que ofrezcan las evidencias que se le atribuyen en el anuncio y que sí se exigen para el registro y aprobación de distribución a la población de un nuevo medicamento.

El anuncio a que se refiere este documento, apareció en la revista Bohemia al menos dos veces: en la edición del 22 de abril de 2011, año 103, no. 8, pág. 67 y en la edición del 20 de mayo del mismo año, no. 10, pág. 22.

Un importante logro de la salud pública cubana en defensa de la salud de la población alcanzado después de 1959 ha sido la eliminación de la publicidad comercial de medicamentos, incluso en revistas especializadas (las llamadas revistas médicas). Esto ocurrió alrededor de 1964, al desaparecer del país la industria privada farmacéutica, las droguerías y las farmacias privadas. También desaparecía la prensa privada burguesa, que se alineó del lado de la contrarrevolución.

Esta evolución está en riesgo de revertirse según lo visto recientemente.

Es una conquista de la ética en salud pública, de la ética de la prensa revolucionaria y es una medida que protege la salud de las personas, que en muchos casos pueden ser inducidas a consumir un producto que puede causarles daño (todo medicamento puede causar efectos adversos), o a no acudir a la ayuda calificada de un servicio de salud, confiando en lo que se anuncia.

Llamamos a la rectificación de la prensa y a las autoridades correspondientes, a eliminar estos anuncios de su política de promoción de algún medicamento.

Al proponer lo anterior no incluimos los mensajes de contenido educativo sobre salud o sobre los programas con perfil preventivo. Ejemplo de estos últimos son los avisos sobre campañas de vacunación en los que se informa fecha y lugar de recibir la vacuna (antipolio, en marzo-abril; antigripe estacional, octubre-noviembre de cada año). También el uso del condón, protector de la infección por VIH y de infecciones de transmisión sexual.

Los trabajadores de la salud deben ser abanderados de la lucha contra las formas no éticas y riesgosas de propaganda de medicamentos, y exigentes en que de cada fármaco, se conozcan las certezas de sus propiedades demostradas en ensayos clínicos controlados.

Prof. Francisco Rojas Ochoa 